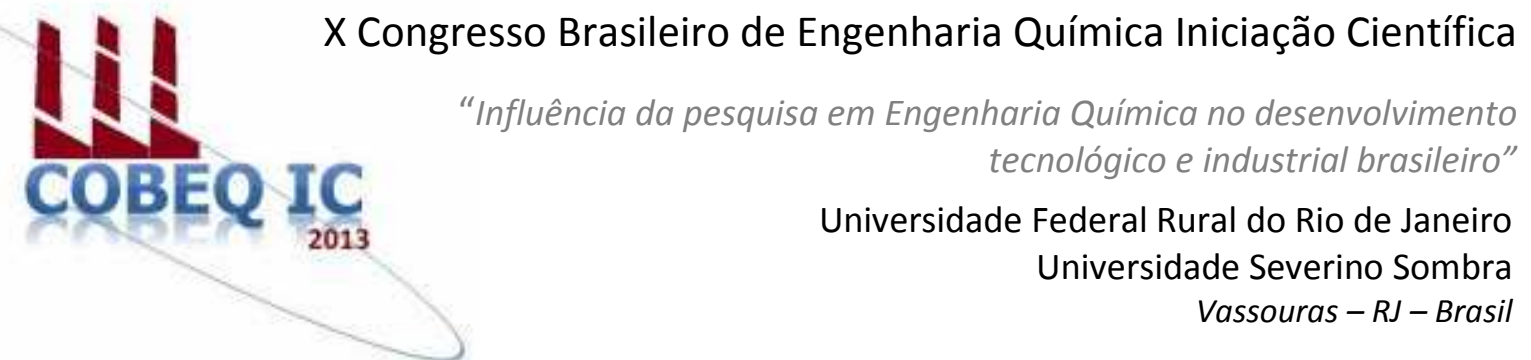

\title{
EXTRAÇÃO E CARACTERIZAÇÃO DE SEMENTES DE FRUTOS DEISCENTES DE LEITEIRO (Mabea fistulifera Mart.)
}

\author{
SIQUEIRA**1 $^{1}$, O. B.; ROSSO ${ }^{2}$, G. A. SARTORI ${ }^{3}$, D.J.M \\ ${ }^{1}$ Aluno do DEQ/UFSCar $\quad{ }^{2}$ Mestranda do PPG-EQ/UFSCar $\quad{ }^{3}$ Professor do DEQ/UFSCar \\ Departamento de Engenharia Química - Universidade Federal de São Carlos \\ Endereço - UFSCar, Rodovia Washington Luís, km 235 - SP 310 - , São Carlos, CEP. 13.565-905 \\ email: sartorid@ufscar.br
}

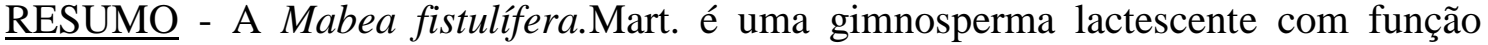
pioneira em florestas tropicais. No interior de frutos capsulares encontram-se as sementes. Após a sua extração, não podem perder a integridade física e a viabilidade dos embriões. Os objetivos consistem na extração das sementes dos frutos, com deiscência explosiva, via diferentes técnicas de secagem e nas caracterizações físicas e fisiológicas destas sementes. A coleta dos frutos realizou-se em árvores matrizes e a extração das sementes via secagem com radiação solar, convecção natural, convecção forçada em estufa e panela drageadora. Através do software Image Pro Plus® determinaram-se os diâmetros mínimo, $(0,59 \pm 0,04) \mathrm{cm}$, médio, $(0,67 \pm 0,04) \mathrm{cm}$, e máximo, $(0,78 \pm 0,05) \mathrm{cm}$, esfericidade, $(0,75 \pm 0,01)$, e via picnometria com hexano, a porosidade $(32 \%)$, massas específicas real $(1,20 \pm 0,01) \mathrm{g} / \mathrm{cm}^{3}$ e aparente $(0,82 \pm 0,01)$ $\mathrm{g} / \mathrm{cm}^{3}$ das sementes. Os experimentos de isoterma, pelo método estático, possibilitaram determinar a umidade de equilíbrio termodinâmico. A avaliação fisiológica, direta em solo, demonstrou a recomposição fisiológica, germinação próxima de $67 \%$ e velocidade de $(1,5 \pm 0,1)$ sementes/dia, valores típicos de sementes das Europhorbiaceae. Todos os métodos viabilizaram o desenvolvimento embrionário, porém a secagem via drageadora ocorreu com o menor tempo de residência, fornecendo sementes com formato oblongo a obovóide, com qualidades físicas e fisiológicas adequadas para reflorestamentos em ecossistemas tropicais.
\end{abstract}

Palavras chave: secagem, propriedades físicas e fisiológicas, recomposição florestal.

\section{INTRODUÇÃO}

As investigações sobre as operações de secagem de frutos e sementes de espécies arbóreas, que se originam a partir de áreas inóspitas, têm sido intensificadas e aumentado de importância nos últimos anos. Principalmente, devido às crescentes ações antrópicas em todos os continentes.
Visando minimizar as modificações resultantes desta atuação humana, poder-se-á recorrer aos processos de reflorestamento e recuperação de áreas degradadas. Recentemente, entre as pesquisas emergentes neste sentido, pode-se citar a revisão feita por Freire et al. (2013), com abordagem sobre as tendências das estratégias de secagem para o tratamento e manejo pós-colheita de sementes 
silvestres. Com base neste enfoque, tem-se como necessidade prima a condução de estudos sobre as sementes da espécie Mabea fistulifera Mart, conhecida popularmente por leiteiro, mamoninha-do-mato, canudeiro ou raiz-de-tiú (Rosso, 2013).

Esta espécie é caracterizada como uma planta lactescente, de 4 a $8 \mathrm{~m}$ de altura com tronco de 20 a $30 \mathrm{~cm}$ de diâmetro e com folhas simples (Lorenzi, 2002). Por ser uma espécie com função pioneira, existe uma grande importância em sua pesquisa, pois, pode ser usada em processos de reflorestamento e recuperação de solos degenerados.

A sua incidência está principalmente nos estados de SP, RJ e MG (Daud e Feres, 2004). Trata-se de uma espécie pioneira, pouco exigente em relação a nutrientes contidos no solo, e é indicada para plantios mistos destinados à recomposição de áreas degradadas.

Seus frutos são capsulares e caracterizados por sua deiscência explosiva, ou seja, podem ser armazenados e quando sofrem a ação de temperaturas mais elevadas passam por um processo de abertura espontâneo liberando as sementes contidas em seu interior. $\mathrm{O}$ fenômeno pode facilmente ser notado pelos estalos provocados por sua explosão (Lorenzi, 2002; Rosso, 2013).

O estudo desta semente é importante, pois sua utilização em processos de reflorestamento seria beneficiada com a utilização do processo de secagem, o que deixaria os embriões mais suscetíveis à germinação e com maior facilidade de armazenamento seguro. Para tal, fazem-se necessárias investigações referentes à caracterização das sementes, onde devem ser determinados os diâmetros mínimo, médio e máximo e a esfericidade, e via picnometria líquida a porosidade, massas específicas real e aparente das sementes.

\section{OBJETIVOS}

Os objetivos consistem na separação das sementes dos frutos, com deiscência explosiva, via diferentes técnicas de secagem e nas caracterizações físicas e fisiológicas destas sementes.

\section{MATERIAIS E MÉTODOS}

\section{Materiais}

Para a realização dos ensaios foram utilizadas sementes de frutos capsulares com deiscência explosiva da espécie $M$. fistulífera. Os frutos foram coletados manualmente de árvores matrizes na região de transição entre o Cerrado e a Mata Semidecidual, próxima à região de São Carlos-SP. A extração das sementes foi realizada via secagem dos frutos, visando a ocorrência da abertura das cápsulas e a liberação das sementes.

\section{Separação das Sementes dos Frutos Capsulares com Deiscência Explosiva}

A extração das sementes foi mediante a secagem dos frutos. Foram testadas, quatro diferentes técnicas de secagem, pois, como se trata de um fruto ainda pouco pesquisado, não se pode precisar a mais apropriada.

A primeira técnica testada foi a secagem via radiação solar, a segunda por meio de convecção natural, em seguida através de convecção forçada em estufa, com temperaturas aproximadas de $30{ }^{\circ} \mathrm{C}$ e por último a secagem em drageadora com velocidade do ar de secagem e temperatura em aproximadamente $\quad 1,5 \mathrm{~m} / \mathrm{s}$ e $40{ }^{\circ} \mathrm{C}$, respectivamente (Figura 1).

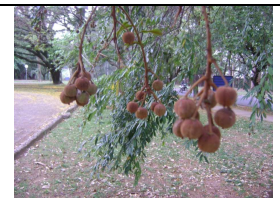

(a)

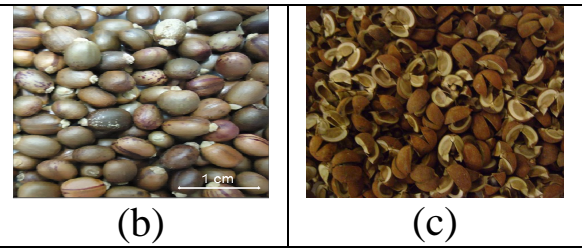

(b) (c)
Figura 1 - Frutos e sementes de $M$. fistulífera (a) frutos antes da coleta, (b) sementes e (c) cascas após a separação.

De acordo com Lorenzi (2002), um quilograma corresponde a aproximadamente 9.600 sementes e sua viabilidade de armazenagem é curta, não ultrapassando seis meses Portanto, as sementes foram armazenadas sob refrigeração, para que os embriões fossem preservados ao longo da condução dos experimentos. Com base em Arrieche et al (2009), os lotes foram armazenados em torno de $4{ }^{\circ} \mathrm{C}$. Os lotes foram homogeneizados, através de um quarteador do tipo Johnes® de 16 canais, com calhas de alimentação e coleta das amostras. 


\section{Equipamentos Utilizados e Determinações das Principais Características Físicas das Sementes}

Durante a caracterização das sementes foi determinado o diâmetro máximo, diâmetro mínimo, diâmetro médio, área projetada, perímetro projetado e a esfericidade das sementes. Para tal foi realizada uma análise de imagens com o auxílio do software Image ProPlus7® (Arrieche et al., 2009) e empregada a relação apresentada na Equação 1, que define a esfericidade como uma relação entre o diâmetro inscrito com o diâmetro circunscrito (Telles e Massarani, 1992).

$$
\phi \equiv \frac{d_{\text {ic }}}{d_{c c}}
$$

A massa específica real foi determinada por meio de picnometria a hélio, a massa específica aparente por meio de picnometria a hexano (Freire et al, 2013). As massas específicas, real e aparente, são obtidas através da Equação 2 e Equação 3, respectivamente, que relacionam a massa e o volume das partículas encontradas.

$$
\rho_{\mathrm{s}}=\left(\mathrm{m} / \mathrm{V}_{\mathrm{s}}\right)
$$

$\rho_{\mathrm{p}}=\left(\mathrm{m} / \mathrm{V}_{\mathrm{p}}\right)$

A porosidade foi obtida através da relação entre a massa específica aparente e a massa específica real, como indicado na Equação 4.

$$
\varepsilon_{p}={ }_{1}-\frac{\rho_{p}}{\rho_{S}}
$$

\section{Análise da Reprodutibilidade dos Dados}

Os dados das propriedades físicas das sementes, advindos dos experimentos e de suas replicatas, foram linearizados através da Equação 5.

$$
\mathrm{M}=\mathrm{a} \cdot \mathrm{M}(\text { replicata })
$$

Esta equação foi utilizada para verificação da reprodutibilidade dos dados em diferentes estudos sobre sementes (Arrieche et al., 2009), substituindo $\mathrm{M}$ pelas respectivas propriedades físicas Dmáx, Dmin, Dmédio, Ap, Pp, W, T' e L, obtidas experimentalmente.

\section{Determinação da Isoterma de Equilíbrio}

$\mathrm{Na}$ determinação da isoterma de equilíbrio termodinâmico, via método gravimétrico, de acordo com Barrozo (1996) e Labuzza (1985), a pesagem das sementes e dos sais utilizados na obtenção da isoterma, foi realizada através de uma balança analítica com precisão de $10^{-4} \mathrm{~g}$, marca Gehaka ${ }$, a isoterma de equilíbrio foi determinada, com o auxílio de uma câmara climatizada Ambi-Hi-Low® Chamber da marca Lab-Line®, modelo 3555425. Os recipientes contendo as amostras de sementes para a obtenção da isoterma possuem dimensões aproximadas de $6 \times 10^{-2} \mathrm{~m}$ de diâmetro e $7 \times 10^{2} \mathrm{~m}$ de altura. De acordo com o esquema mostrado na Figura 2.

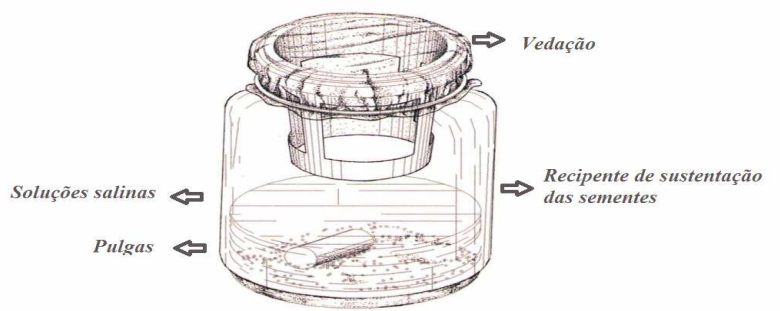

Figura 2 - Esquema dos recipientes contendo as sementes (Picelli et al., 2009).

A homogeneização das soluções salinas foi feita por meio de um agitador magnético da marca Fisatom®. Trata-se de uma operação fundamental na homogeneização e mistura dos materiais que deve ser conduzida durante a sorção. Para a obtenção da isoterma de equilíbrio foi usada uma estufa da marca FANEM®, para a determinação da umidade das sementes via método da estufa a $(105 \pm 3)$ ${ }^{\circ} \mathrm{C}$, por $24 \mathrm{~h}$ (AOAC, 2000).

\section{Testes de Avaliação da Qualidade Fisiológica dos Embriões}

A avaliação da qualidade fisiológica das sementes foi conduzida com o intuito de se conhecer o crescimento dos embriões germinados, através de método direto em condições de campo.

Os testes de germinação foram conduzidos com base nas Regras de Análise de Sementes (ISTA, 2000). A avaliação da germinação das sementes de $M$. fistulífera via método direto, em campo, foi realizada em 
condições naturais de solo no Horto Florestal Navarro de Andrade, São Carlos-SP.

Para tanto, foram semeados em lanços os lotes de sementes em canteiros com solo adubado contendo Tropstrato ${ }^{\circledR}$ florestal e adubo com estercos de origens animal e vegetal, onde 100 sementes de $M$. fistulífera foram lançadas na terra preparada e recobertas com o substrato orgânico.

Os resultados obtidos na avaliação da qualidade fisiológica das sementes foram tratados com o auxílio da Equação 6 e, assim, determinado o índice de germinação das sementes "in natura".

\section{$G E \equiv \frac{\text { Sementes germinadas }}{\text { Total de sementes da amostra }}$}

Concluídas as determinações físicas e fisiológicas, as amostras de sementes foram armazenadas em recipientes hermeticamente fechados e conservados sob refrigeração de aproximadamente $4{ }^{\circ} \mathrm{C}$ (Arrieche et al., 2009).

\section{RESULTADOS}

Durante os experimentos foi possível verificar que a separação na drageadora apresentou melhores resultados em relação ao tempo de residência dos frutos no processo de secagem, com abertura total dos frutos após aproximadamente $6 \mathrm{~h}$ e sementes mais sadias, que as obtidas pelos outros processos. Porém no caso de se adotar critérios do ponto de vista econômico e ecológico, bem como, considerando que o rendimento (Tabela 1) corresponde ao total de frutos abertos em relação ao total de frutos expostos à secagem, tem-se que o melhor método é a secagem via radiação, pois emprega a energia proveniente dos raios solares e apresenta sementes tão saudáveis quanto às obtidas na drageadora, com o mesmo rendimento de $100 \%$.

Tabela 1 - Resultados obtidos com os diferentes métodos de secagem utilizados.

\begin{tabular}{|c|c|c|c|}
\hline Métodosde secagem & Duração & Caracteristicas (Cor semente) & Rendimento \\
\hline Radiação solar & $24 h$ a 48 h & Marrom vivo & $100 \%$ \\
\hline Convecçãoforçada & $72 h$ a $96 h$ & Marrom escuro & $97 \%$ \\
\hline Draggeadora & $6 h$ & Marrom vivo & $100 \%$ \\
\hline Convecção natural & 120 a 168h & Marrom escuro com manchas cinzas & $85 \%$ \\
\hline
\end{tabular}

As diferenças entre as médias dos diâmetros máximos e mínimos são inferiores aos intervalos de desvios obtidos para cada análise em cada método empregado, o que levou à homogeneização dos lotes em um quarteador do tipo Johnes®, 16 canais. Após a obtenção do lote homogêneo, foi feita uma nova avaliação das sementes em relação aos diâmetros máximo, médio, mínimo, área projetada e o perímetro projetado. Para tanto, foi utilizado o software de análise de imagens Image Pro Plus®, conforme a Tabela 2.

Tabela 2 - Propriedades físicas*.

\begin{tabular}{|c|c|c|c|c|c|c|}
\hline Propriedade & $\begin{array}{c}\text { Valor } \\
\text { Médio }\end{array}$ & $\begin{array}{c}\text { Parâmetro } \\
\mathbf{a}\end{array}$ & $\begin{array}{c}\text { Desvio- } \\
\text { padrão }\end{array}$ & $\begin{array}{c}\text { Coeficiente } \\
\text { correlação }\end{array}$ & $\begin{array}{c}\text { Teste- } \\
\mathrm{t}\end{array}$ & $\begin{array}{c}\text { Variância } \\
\text { Explicada } \\
(\%)\end{array}$ \\
\hline Dmáx $(\mathrm{cm})$ & $0,78 \pm 0,05$ & 1,03 & 0,0004 & 99,91 & 2469,3 & 99,83 \\
\hline Dmin $(\mathrm{cm})$ & $0,59 \pm 0,04$ & 1,03 & 0,0005 & 99,88 & 1878,9 & 99,76 \\
\hline Dmédio $(\mathrm{cm})$ & $0,67 \pm 0,04$ & 0,98 & 0,0001 & 99,98 & 6691,2 & 99,97 \\
\hline $\mathrm{Ap}\left(\mathrm{cm}^{2}\right)$ & $0,36 \pm 0,05$ & 0,94 & 0,0002 & 99,99 & 4543,7 & 99,98 \\
\hline $\mathrm{Pp}(\mathrm{cm})$ & $2,49 \pm 0,14$ & 0,97 & 0,0003 & 99,92 & 2610,3 & 99,94 \\
\hline
\end{tabular}

(*) nível de significância de $5 \%$ e p-valor < 0,001.

Outro teste realizado foi o de mensurar as dimensões das sementes, via micrômetro, a partir do comprimento, espessura e largura, conforme especificado na Figura 5. Estes valores estão reunidos na Tabela 3 .

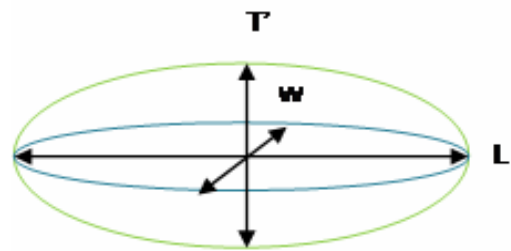

Figura 5 - Esquema das dimensões analisadas da semente (Rosso, 2013).

Tabela 3 - Dados das dimensões das sementes via micrômetro digital*.

\begin{tabular}{|c|c|c|c|c|c|c|}
\hline $\begin{array}{c}\text { Dimensão } \\
(\mathrm{cm})\end{array}$ & Média & $\begin{array}{c}\text { Parâmetro } \\
\mathbf{a}\end{array}$ & $\begin{array}{c}\text { Desvio- } \\
\text { Padrão }\end{array}$ & $\begin{array}{c}\text { Coeficiente } \\
\text { correlação }\end{array}$ & $\begin{array}{c}\text { Teste } \\
-\mathrm{t}\end{array}$ & $\begin{array}{c}\text { Variância } \\
\text { Explicada } \\
(\%)\end{array}$ \\
\hline$(\mathbf{W})$ & $0,58 \pm 0,34$ & 0,9981 & 0,0017 & 99,12 & 577,0 & 98,25 \\
\hline$\left(\mathbf{T}^{\prime}\right)$ & $0,50 \pm 0,50$ & 0,9959 & 0,9959 & 99,64 & 614,3 & 99,28 \\
\hline$(\mathbf{L})$ & $0,77 \pm 0,43$ & 0,9985 & 0,0012 & 99,60 & 769,8 & 99,21 \\
\hline
\end{tabular}

(*) nível de significância de 5\% e p-valor < 0,001.

Tanto na Tabela 2 quanto na Tabela 3 os parâmentos estatísticos foram calculados utilizando o software STATISTICA®. Pode-se observar que a reprodutibilidade dos dados está assegurada, pois os valores encontrados para o parâmetro a (Equação 5) foram próximos de um, o desvio-padrão foi baixo, o teste $\mathrm{t}$ alto e a variância explicada não está abaixo de 98,25\% em nenhum dos casos avaliados. Os valores de p permitem assegurar a validade de a com elevado grau de 
confiança. Em decorrência desta confiabilidade, tem-se que os dados obtidos via micrômetro estão de acordo com os valores encontrados com o software de análise de imagens Image Pro Plus ${ }^{\circledR}$.

Com os dados da Tabela 2 e a partir da Equação 1, foi possível determinar a esfericidade das sementes, fornecendo o valor de $(0,75 \pm 0,01)$.

Também se determinou que a quantidade de sementes encontradas em dez gramas de amostra foi de $(101 \pm 4)$ unidades, o que era esperado de acordo com Lorenzi (2008), pois corresponde a um valor condizente com os encontrados na literatura. Determinou-se que a umidade inicial das sementes extraídas das tricocas foi de $(7,3 \pm 0,3) \%$ b.u, conforme era esperado devido ao processo de extração via secagem do pericarpo.

A determinação da massa específica real via Equação 2 apresentou como resultado o valor médio de $(1,20 \pm 0,01) \mathrm{g} / \mathrm{cm}^{3}$. Quando avaliada a massa específica aparente, através da técnica de picnometria líquida com hexano, foi verificado um valor de $(0,82 \pm 0,01) \mathrm{g} / \mathrm{cm}^{3}$.

Também foi possível obter os valores da umidade de equilíbrio termodinâmico, considerando o processo de adsorção de umidade das partículas na temperatura de aproximadamente $40{ }^{\circ} \mathrm{C}$ para as sementes de M. fistulífera. Os dados foram ajustados a equações empíricas e semi-empíricas existentes na literatura para partículas orgânicas (Basu et al., 2006; Rosso, 2013) e via análise estatística foram obtidos os ajustes dos parâmetros das equações (melhor representado pelo modelo GAB). Sendo que, na Figura 7, tem-se apresentado o ajuste da equação clássica de GAB aos dados experimentais (Basu et al., 2006).

A curva obtida (Figura 7) apresenta comportamento típico de isoterma de adsorção, conforme era esperado para o processo de adsorção de umidade de sementes silvestres nestas condições, de acordo com Basu et al. (2006) e Picelli et al. (2009).

Com base na avaliação da germinação das sementes via método direto em solo, foi realizado o plantio das sementes em canteiros do Horto Florestal Navarro de Andrade. Onde as sementes "in natura", após a extração das tricocas, foram semeadas. Verificou-se que as mudas após 27 dias da semeadura apresentavam uma germinação de $46 \%$.

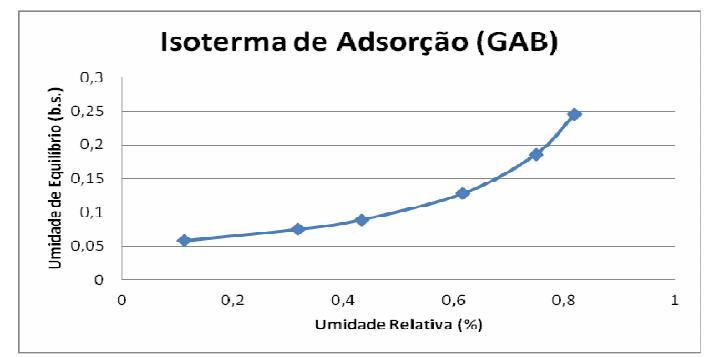

Figura 7 - Isoterma de adsorção de umidade de equilíbrio, a $40{ }^{\circ} \mathrm{C}$, para as sementes de leiteiro.

Depois de decorridos 40 dias do plantio, $67 \%$ das sementes haviam germinado, isto resulta em uma velocidade de germinação média de $(1,5 \pm 0,1)$ sementes/dia. Este resultado já era esperado, pois segundo Lorenzi (2008), é típico para sementes silvestres pioneiras. Na Figura 8 tem-se uma foto típica de um dos canteiros dos viveiros de mudas no qual foram semeadas a lanço as sementes de $M$. fistulífera.

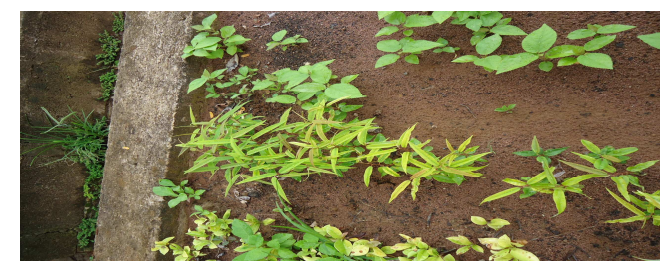

\section{Figura 8 - Foto das plântulas em desenvolvimento no solo do canteiro.}

Após 40 dias da semeadura, as mudas de M. fistulifera apresentavam aproximadamente 4 folhas por planta, com sistema radicular em torno de $7 \mathrm{~cm}$ e parte aérea em torno de $6 \mathrm{~cm}$.

Constatou-se que o desenvolvimento radicular das sementes de $M$. fistulífera ocorre entre 21 e 30 dias. Assim como ocorre com as sementes de Tapiá (Alchomea triplinervia. Mueller), família das Europhorbiaceae de frutos deiscentes, que ocorre entre 21 e 50 dias (Rosso, 2013).

\section{CONCLUSÃO}

Os métodos utilizados para a coleta, extração, avaliação fisiológica e obtenção da isoterma das sementes da $M$. fistulifera foram adequados. Permitindo obter amostras com $100 \%$ de pureza, além de tornar possíveis as determinações das umidades de equilíbrio 
termodinâmico. A verificação da reprodutibilidade estatística dos dados foi possível via análise de parâmetros estatísticos.

As operações de secagem utilizadas mostraram-se adequadas para as reduções de umidades dos frutos. Sendo a radiação solar a que apresentou maior velocidade de abertura do pericarpo, possibilitando a extração da semente. A determinação das propriedades físicas utilizando o software Image Pro-Plus ${ }^{\circledR}$, também, foi adequada para a espécie de semente estudada.

Os ajustes dos parâmetros de equações advindas da literatura aos dados mostraram que, entre as equações analisadas, o melhor ajuste foi para a equação do modelo de GAB.

Os dados foram ajustados segundo equações empíricas e semi-empíricas existentes na literatura para partículas orgânicas e via análise estatística foram obtidos os ajustes dos parâmetros das equações (melhor representado pelo modelo GAB).

Também foi possível obter informações referentes à recomposição fisiológica das sementes desta espécie silvestre pioneira.

\section{NOMENCLATURA}

$\begin{array}{llc}\text { A } & \text { parâmetro da Equação 5 } & {[-]} \\ \text { a } & \text { área } & {\left[\mathrm{L}^{2}\right]} \\ \text { b.s., b.u. } & \text { base seca e base úmida } & {[-]} \\ \text { D } & \text { diâmetro } & {[\mathrm{L}]} \\ \text { dcc, dic } & \text { diâmetros circunscrito, inscrito } & {[\mathrm{L}]} \\ \text { GE } & \text { germinação, Equação 6 } & {[-]} \\ \text { L } & \text { espessura } & {[\mathrm{L}]} \\ \text { M } & \text { dados de um experimento } & {[-]} \\ \text { m } & \text { massa } & {[\mathrm{M}]} \\ \mathrm{M}_{\text {(replicata) }} & \text { dados do teste replicata } & {[-]} \\ \text { P, T } & \text { perímetro e largura } & {[\mathrm{L}]} \\ \text { V, W } & \text { volume e comprimento } & {\left[\mathrm{L}^{3}\right]}\end{array}$

\section{Subscritos}

$\begin{array}{lrlr}\text { Max } & \text { Maximo } & \text { Min } & \text { Mínimo } \\ \text { Médio } & \text { Médio } & \mathrm{p} & \text { Partícula }\end{array}$

s Sólido ou real

\begin{tabular}{llc}
\multicolumn{2}{l}{ Símbolos Gregos } & \\
$\varepsilon_{\mathrm{p}}$ & porosidade & {$[-]$} \\
$\Phi$ & esfericidade & {$[-]$} \\
$\rho_{\mathrm{s}}$ & massa específica real & {$\left[\mathrm{M} \mathrm{L}^{3}\right]$} \\
$\rho_{\mathrm{p}}$ & massa específica aparente & {$\left[\mathrm{M} \mathrm{L}^{3}\right]$}
\end{tabular}

\section{REFERÊNCIAS}

AOAC. (2000) Official Methods of Analysis, Maryland, Ass. Of. Anal. Chem., USA
ARRIECHE, L. S.; PICELLI, R. M.; SARTORI, D. T. M. (2009) Secagem de sementes arbóreas pioneiras em leito fluidizado. Anais do $34^{\circ}$ ENEMP, 10p., $\mathrm{CD}$, Campinas, SP

BARROZO, M. A. S. (1995) Transferência de calor e massa entre o ar e sementes de soja em leitos deslizantes e escoamentos cruzados. Tese de doutorado, PPGEQ/UFSCar, São Carlos, SP, 163p.

BASU, S.; SHIVHARE, U. S., MUJUMDAR, A. S. (2006) Models for Sorption Isotherms for Foods: a Review. DRT, v.24(8), p. 917-930.

DAUD, R. D.; FERES, R.J.F. (2004) O valor de $M$. fistulifera, planta nativa do Brasil, como reservatório para o predador $\mathrm{E}$. citrifolius, Rev. Bras. Zool. vol.21 n.3, p. 38-46 Curitiba,.

FREIRE, J.TY.; SARTORI, D.J.M.; FREIRE, F.B.; HUGO, P (2013) Drying Strategies for the Postharvest Management of Wild Seeds. Stewart Postharvest Review, v. 9, p. $1-5$

ISTA (2010) International Seed Testing Association, Muschick M. Ed. Bassersdorf, Switzerland.:68pp.

LABUZZA, T. P.; KAANANE, A.; CHEN, J. Y. (1985) Effect of Temperature on the Moisture Sorption Isotherms and Water Activity Shift of Two Dehydrated Foods. J.Food Sc., v.50, p.385-390.

LORENZI, H. (2002) Árvores brasileiras: manual de identificação e cultivo de plantas arbóreas do Brasil. Nova Odessa: Plantarum, v.1, 368p.

MASSARANI, G.; TELLES, A. S. (1992) Aspectos da secagem de material sólido particulado. In:Freire, J. T. e Sartori, D.J.M. Tópicos Especiais em Secagem. São Carlos, v.1, ed. UFSCar, p. 1-39.

PICELLI, R.M.; ARRIECHE L. S., SARTORI, D. J. M. (2009) Umidade de equilíbrio de sementes pioneiras: isotermas de dessorção e adsorção para C. glaziovi. Anais VIII COBEQ-IC, CD Rom Uberlândia, MG.

ROSSO GA. (2013) Recobrimento de sementes de frutos silvestres em panela rotatória. Tese, PPGEQ/, UFSCar. 117 p.

\section{AGRADECIMENTOS}

Ao apoio financeiro recebido do $\mathrm{CNPq}$, CAPES, Horto Florestal Navarro de AndradeSP, PRONEX/CNPq, FAPESP e ao Programa IC, Processo N ${ }^{0}$ 043/2012 - PROPQ/UFSCar. 